\title{
Family history of breast cancer and young age at diagnosis of breast cancer increase risk of second primary malignancies in women: a population-based cohort study
}

\author{
M Prochazka*,', P Hall', F Granath ${ }^{2}$ and K Czene' \\ 'Department of Medical Epidemiology and Biostatistics, Karolinska Institutet, PO Box 28I, SE- 17177 Stockholm, Sweden; ${ }^{2}$ Department of Medicine at \\ Karolinska University Hospital, Clinical Epidemiology Unit, SE-I 7 I 76 Stockholm, Sweden
}

\begin{abstract}
Among 152600 breast cancer patients diagnosed during 1958-2000, there was a 22\% increased risk of developing a second primary non-breast malignancy (standardised incidence ratio $(\mathrm{SIR})=1.22$; $95 \%$ confidence interval $(\mathrm{Cl})$ : 1.19-1.24). The highest risk was seen for connective tissue cancer $(\mathrm{SIR}=1.78 ; 95 \% \mathrm{Cl}$ : 1.49-2.10). Increased risks were noted among women diagnosed with breast cancer before age 50. Oesophagus cancer and non-Hodgkin's lymphoma showed six-and four-fold higher risks, respectively, in women with a family history of breast cancer compared to those without in the $\geqslant 10$-year follow-up period.
\end{abstract}

British Journal of Cancer (2006) 95, I29 I- 1295. doi: I 0. I038/sj.bjc.6603404 www.bjcancer.com

Published online 3 October 2006

(c) 2006 Cancer Research UK

Keywords: breast cancer; second primary cancer; familial risk

With advances in early diagnosis and treatment, for many women breast cancer is becoming increasingly curable. Breast cancer survivors have been reported as having a $10-60 \%$ increased risk of a second primary malignancy at other sites compared to the general population (Mellemkjaer et al, 2006; Raymond and Hogue, 2006; Yu et al, 2006). Multiple primary tumours may be caused by shared aetiological factors (e.g. diet, reproductive history, hormonal status, and environmental exposure), inherited susceptibility, adverse effects of treatment, increased medical surveillance, and possible interactions between these factors (Travis, 2002; Suzuki et al, 2005). Up to $7 \%$ of breast cancer cases are estimated to be due to breast cancer susceptibility genes (e.g. BRCA1, BRCA2, $p 53$, and PTEN) (Edlich et al, 2005), adding to the risk of other cancers (Edlich et al, 2005; McClain et al, 2005).

Most breast cancer patients will die of causes other than breast cancer; so the long-term effects of treatment have become correspondingly important (Shapiro and Recht, 1994). Increased risks of soft tissue sarcomas (Karlsson et al, 1998; Levi et al, 2003), lung (Prochazka et al, 2002, 2005), and oesophageal cancer (Zablotska et al, 2005) have been associated with radiotherapy of the breast. In addition, a causal relationship between tamoxifen and endometrial cancer risk has been established (Bergman et al, 2000; Swerdlow and Jones, 2005).

We aimed to examine the risk of second malignancies in women with breast cancer, according to age at and time interval since breast cancer diagnosis, and calendar period. In addition, we investigated the effect of family history of breast cancer.

*Correspondence: Dr M Prochazka; E-mail: Michaela.Prochazka@ki.se Received 10 July 2006; revised 23 August 2006; accepted 6 September 2006; published online 3 October 2006

\section{MATERIALS AND METHODS}

Eligible patients included 171386 women with histologically confirmed invasive breast cancer as the first cancer reported to the Swedish Cancer Registry between 1958 and 2000. The Swedish Cancer Registry receives reports on newly diagnosed cancers from both pathologists/cytologists and physicians. Reporting to the register is compulsory, and $96 \%$ of all cancers in Sweden are reported (Mattsson and Wallgren, 1984). Almost all diagnosed breast cancer patients in Sweden are treated within the national health care system and treatment regimens are similar throughout the country.

The breast cancer cohort was matched with the Swedish Emigration and Cause of Death Registries. Excluded were women diagnosed with a second cancer $(n=7370)$ or dying $(n=3547)$ within 1 month after the first primary cancer. Additional exclusions included women identified as immigrants as data on previous cancers were unavailable, and women who had emigrated before the diagnosis of breast cancer and left Sweden for $\geqslant 1$ year $(n=7883)$. Thus, 152586 women were included in the study. A four-digit diagnostic code according to the seventh revision of the International Classification of Diseases (ICD-7) was used. The following ICD-7 codes were pooled: 'upper aerodigestive tract', codes 140-141, 143-148, and 161; 'colorectum', codes 153-154; 'liver', codes 155-156; 'non-Hodgkin's lymphoma', codes 200 and 202; and 'leukaemia', codes 204-207.

Our database for analysis of risk for second primary malignancies according to family history of breast cancer was created by a link between the Cancer Registry from 1958 to 2000 and Multigeneration Register using the individually unique national registration number. Statistics Sweden maintains a Multigeneration Register where offspring born in Sweden in 1932 and later are registered with their biological parents as families (Hemminki et al, 2001). At present, it includes 11 million individuals, who are 
structured in 3.1 millions of nuclear families. Breast cancer history was collected on all first-degree relatives, namely parents, siblings, and offspring, and if positive, this is described in this paper as 'with a family history'.

\section{Statistical methods}

Standardised incidence ratios (SIRs) were calculated by dividing the observed number of second primary cancers by the number expected based on population rates. The observed number of cases was assumed to be Poisson distributed, and 95\% confidence intervals (CIs) for SIR were calculated (Breslow and Day, 1987). Person years at risk were calculated as starting at date of breast cancer diagnosis and ending at date of death, emigration, second primary cancer diagnosis, or 31 December 2000, whichever date came first. The expected number of cancers was estimated by multiplying the age-, sex-, and calendar year-specific rates from the Swedish Cancer Registry by the accumulated person years at risk. The follow-up period was divided into 1-9 years and 10 or more years after breast cancer diagnosis. The all sites SIRs combine the specific cancer sites presented in each table.

The SIRs for second primary malignancies according to family history of breast cancer were calculated similarly, except that the expected numbers of cancers were obtained using age-, sex-, and calendar year-specific rates in the corresponding general population in our database. The ratio of SIR with a family history to SIR without a family history was calculated to easily compare these two groups, and 95\% CIs were estimated (Clayton and Hill, 1993). Similarly, the ratio of SIR for women $<50$ years of age at breast cancer diagnosis to that $\geqslant 50$ years was calculated.

\section{RESULTS}

Table 1 presents SIRs by specific sites of subsequent cancers. A $22 \%$ increased risk of a second primary malignancy other than breast cancer was found. The largest significant excess risk was found for

Table I Number of observed second primary cancers (Obs) following breast cancer, diagnosed between 1958 and 2000, standardised incidence ratios (SIRs), and $95 \%$ confidence interval $(\mathrm{Cl})$ among women

\begin{tabular}{|c|c|c|c|}
\hline Second primary cancer site & Obs & SIR & $95 \% \mathrm{Cl}$ \\
\hline Upper aerodigestive tract & 137 & 0.89 & $(0.75-1.04)$ \\
\hline Salivary glands & 43 & 1.67 & $(1.21-2.20)$ \\
\hline Oesophagus & 116 & 1.57 & (I.24- I.78) \\
\hline Stomach & 686 & 1.40 & $(1.30-1.51)$ \\
\hline Small intestine & 76 & 1.29 & $(1.02-1.60)$ \\
\hline Colorectum & 1923 & 1.15 & $(1.10-1.20)$ \\
\hline Liver & 451 & 0.92 & $(0.84-1.01)$ \\
\hline Pancreas & 471 & 1.12 & $(1.02-1.22)$ \\
\hline Lung & 717 & 1.37 & $(1.27-1.47)$ \\
\hline Cervix & 217 & 0.92 & $(0.80-1.05)$ \\
\hline Endometrium & 1006 & 1.54 & $(1.44-1.63)$ \\
\hline Ovary & 712 & 1.28 & $(1.19-1.38)$ \\
\hline Kidney & 443 & $|.3|$ & $(1.19-1.44)$ \\
\hline Urinary organs & 383 & 1.10 & $(0.99-1.21)$ \\
\hline Melanoma & 360 & 1.27 & $(1.14-1.40)$ \\
\hline Nervous system & 367 & 1.16 & $(1.05-1.28)$ \\
\hline Thyroid & 164 & 1.55 & $(1.32-1.80)$ \\
\hline Endocrine glands & 270 & 1.08 & $(1.96-1.22)$ \\
\hline Bone & 21 & 1.68 & (1.04-2.48) \\
\hline Connective tissue & 129 & 1.78 & $(1.49-2.10)$ \\
\hline Non-Hodgkin's lymphoma & 390 & 1.13 & $(1.02-1.25)$ \\
\hline Hodgkin's disease & 38 & 1.05 & $(0.74-1.41)$ \\
\hline Multiple myeloma, plasmocytoma & 182 & 1.04 & $(0.89-1.20)$ \\
\hline Leukaemia & 343 & 1.37 & $(1.23-1.52)$ \\
\hline All the above sites & 9758 & 1.22 & $(1.19-1.24)$ \\
\hline
\end{tabular}

Bold denotes statistical significance. connective tissue cancer $(\mathrm{SIR}=1.78 ; 95 \%$ CI: $1.49-2.10)$. In addition, we investigated cancer sites stratified by time since breast cancer diagnosis, $1-9$ and $\geqslant 10$ years (data not shown). Sites with SIRs that were significantly higher for the longer follow-up period were lung cancer $(\mathrm{SIR}=1.00,95 \% \mathrm{CI}=0.89-1.11, n=316$ vs $\mathrm{SIR}=1.92, \quad 95 \% \mathrm{CI}=1.74-2.12, \quad n=401)$ and non-Hodgkin's lymphoma (NHL) $(\mathrm{SIR}=0.93,95 \% \mathrm{CI}=0.80-1.06, n=188$ vs $\mathrm{SIR}=1.42,95 \% \mathrm{CI}=1.23-1.64, n=202)$. In contrast, significantly elevated SIRs that were higher for the shorter follow-up period were observed for cancers of the endometrium (SIR $=1.65$, $95 \% \mathrm{CI}=1.53-1.78, n=671$ vs $\mathrm{SIR}=1.35,95 \% \mathrm{CI}=1.21-1.50$, $n=335)$ and central nervous system $(\mathrm{SIR}=1.25,95 \% \mathrm{CI}=1.10-$ $1.41, n=254$ vs $\mathrm{SIR}=1.00,95 \% \mathrm{CI}=0.82-1.20, n=113)$.

The effect of calendar period (1958-1979 vs 1980-2000) of breast cancer diagnosis was also studied (data not shown). In order to restrict the problem with truncation, the risk was estimated only for follow-up periods 1-9 and 10-14 years after breast cancer diagnosis. There were no apparent differences in risk by calendar period, even after taking time since breast cancer diagnosis into consideration, except for endometrial cancer where the risk in those followed for 10-14 years was higher for the later $(\mathrm{SIR}=1.67$, $95 \%$ CI: $1.32-2.06, n=77)$ compared to the earlier $(\mathrm{SIR}=1.25$, 95\% CI: $0.99-1.54, n=79)$ period.

Standardised incidence ratios stratified by age $(<50$ and $>50$ years) for selected sites with a significantly elevated overall SIR and at least 100 observed cancers are presented in Table 2. Standardised incidence ratios were also calculated separately for subcategories of leukaemia and for connective tissue cancers in the thorax or upper limbs, areas more likely to be in the radiation treatment field. For most cancers, the risk decreased with increasing age at breast cancer diagnosis, the higher risk ratio for younger compared to older women for cancers at all sites combined being 1.36. Cancer sites where the significant ratio was higher than 1.50 were oesophagus (ratio 1.84), stomach (ratio 1.65), pancreas (ratio 1.51), lung (ratio 2.07), ovary (ratio 1.82), thyroid (ratio 1.62), and connective tissue (ratio 2.21), particularly thorax and upper limbs (ratio 2.32). A significantly higher risk of leukaemia (reflecting the patterns observed for acute and chronic myeloid leukaemia) was seen in younger compared to older women 1-9 years after diagnosis of breast cancer $(\mathrm{SIR}=2.86$, $95 \% \mathrm{CI}=1.90-4.02, \quad n=28$ vs $\mathrm{SIR}=1.28,95 \% \mathrm{CI}=1.10-1.47$, $n=185$; ratio $=2.23$ ), but this difference diminished in the later follow-up period $\quad(\mathrm{SIR}=1.38,95 \% \quad \mathrm{CI}=0.95-1.94, \quad n=33$ vs $\mathrm{SIR}=1.33,95 \% \mathrm{CI}=1.08-1.63, n=97 ;$ ratio $=1.04)$. A similar pattern was seen for connective tissue cancer (SIR $=4.72,95 \%$ $\mathrm{CI}=2.92-6.95, n=21$ vs $\mathrm{SIR}=1.19,95 \% \mathrm{CI}=0.88-1.56, n=48$; ratio $=3.97)$, particularly of the thorax and upper limbs $(\operatorname{SIR}=11.11$, $95 \% \mathrm{CI}=5.51-18.65, n=11$ vs $\mathrm{SIR}=2.79,95 \% \mathrm{CI}=1.77-4.05$, $n=23$; ratio $=3.98$ ). For endometrial cancer, a statistically higher risk for older compared to younger women (SIR $=1.15,95 \%$ $\mathrm{CI}=0.86-1.47, n=55$ vs $\mathrm{SIR}=1.72,95 \% \mathrm{CI}=1.59-1.86, n=616$; ratio 0.67$)$ was observed in the 1 - to 9 -year follow-up period.

Risks of second primary cancers for women with and without a family history of breast cancer are presented in Table 3 . Significantly higher risks analysed as a ratio between women with and without a family history were seen for cancer of the oesophagus, stomach, ovary, NHL, and leukaemia. The highest SIRs were seen for second primary cancers of the oesophagus $(\mathrm{SIR}=7.54,95 \% \mathrm{CI}=2.38-15.60, n=5)$ and $\mathrm{NHL}(\mathrm{SIR}=6.10$, $95 \% \mathrm{CI}=3.67-9.16, n=19)$ among women with a family history in the $\geqslant 10$ year follow-up period. Their respective ratios comparing women with and without a family history were statistically significant (5.89 and 4.33).

\section{DISCUSSION}

Multiple malignancies may reflect increased surveillance, previous therapy, shared aetiological (e.g. lifestyle) factors, and genetic 
Table 2 Number of observed second primary cancers (Obs) following breast cancer, diagnosed between 1958 and 2000, standardised incidence ratios (SIRs), and 95\% confidence interval (Cl) for second primary malignancy according to age at breast cancer diagnosis

Age at breast cancer diagnosis

\begin{tabular}{|c|c|c|c|c|c|c|c|}
\hline Second primary cancer site & \multicolumn{3}{|c|}{$<\mathbf{5 0}$ years } & \multicolumn{3}{|c|}{$\geqslant 50$ years } & Ratio \\
\hline Colorectum & 278 & 1.38 & $(1.23-1.58)$ & 1645 & 1.12 & $(1.06-1.17)$ & $1.24 *$ \\
\hline Pancreas & 74 & 1.60 & $(1.26-1.99)$ & 397 & 1.06 & $(0.96-1.16)$ & $1.51 *$ \\
\hline Lung & 235 & 2.35 & $(2.06-2.66)$ & 482 & 1.14 & $(1.04-1.24)$ & $2.07 *$ \\
\hline Kidney & 74 & 1.50 & $(1.18-1.86)$ & 369 & 1.28 & $(1.15-1.41)$ & 1.17 \\
\hline Melanoma & 91 & 1.32 & $(1.06-1.61)$ & 269 & 1.25 & $(1.10-1.40)$ & 1.06 \\
\hline Nervous system & 89 & 1.25 & $(1.00-1.52)$ & 278 & 1.14 & $(1.01-1.27)$ & 1.10 \\
\hline Thyroid & 51 & 2.21 & $(1.65-2.86)$ & 113 & 1.36 & $(1.12-1.63)$ & $1.62 *$ \\
\hline Endocrine glands & 75 & 1.36 & $(1.07-1.68)$ & 195 & 1.01 & $(0.87-1.15)$ & $1.35 *$ \\
\hline Connective tissue & 40 & 3.27 & $(2.33-4.36)$ & 89 & 1.48 & $(1.19-1.80)$ & $2.21 *$ \\
\hline Thorax and upper limbs & 19 & 8.02 & $(4.82-12.03)$ & 42 & 3.46 & $(2.49-4.58)$ & $2.32 *$ \\
\hline Chronic myeloid leukaemia & 13 & 2.89 & $(1.53-4.67)$ & 33 & 1.56 & $(1.08-2.14)$ & 1.85 \\
\hline All the above sites & 1692 & 1.64 & $(1.56-1.72)$ & 6405 & 1.20 & $(1.17-1.23)$ & $1.36 *$ \\
\hline
\end{tabular}

Standardised incidence ratio for women $<50$ years of age at breast cancer diagnosis was compared with SIR for women $\geqslant 50$ years of age at breast cancer diagnosis (ratio). Bold denotes statistical significance; * denotes statistically significant ratio.

Table 3 Number of observed second primary cancers (Obs) following breast cancer, diagnosed between 1958 and 2000, standardised incidence ratios (SIRs), and 95\% confidence interval (Cl) for second primary malignancy according to family history of breast cancer

\begin{tabular}{|c|c|c|c|c|c|c|c|}
\hline Second primary cancer site & \multicolumn{6}{|c|}{ Family history of breast cancer } & Ratio \\
\hline Oesophagus & 7 & 3.76 & $(1.49-7.07)$ & 58 & 1.69 & $(1.29-2.16)$ & $2.22 *$ \\
\hline Stomach & 27 & 2.65 & $(1.74-3.74)$ & 296 & 1.41 & $(1.26-1.58)$ & $1.88 *$ \\
\hline Colorectum & 46 & 1.10 & $(0.8 \mathrm{I}-1.45)$ & 1010 & 1.18 & $(1.11-1.25)$ & 0.93 \\
\hline Endometrium & 41 & 1.94 & $(1.39-2.58)$ & 589 & 1.45 & $(1.34-1.57)$ & 1.33 \\
\hline Ovary & 40 & 2.32 & $(1.66-3.10)$ & 437 & 1.38 & $(1.25-1.51)$ & $1.68 *$ \\
\hline Kidney & 8 & 0.89 & $(0.38-1.61)$ & 239 & 1.29 & $(1.14-1.46)$ & 0.69 \\
\hline Melanoma & 18 & 1.67 & $(1.00-2.53)$ & 231 & 1.28 & $(1.12-1.45)$ & 1.31 \\
\hline Nervous system & 13 & 1.20 & $(0.63-1.94)$ & 236 & 1.25 & $(1.09-1.41)$ & 0.96 \\
\hline Thyroid & 5 & 1.51 & $(0.48-3.12)$ & 104 & 1.78 & $(1.46-2.14)$ & 0.85 \\
\hline Endocrine glands & 12 & 1.37 & $(0.70-2.25)$ & 199 & 1.19 & $(1.03-1.36)$ & 1.15 \\
\hline
\end{tabular}

Standardised incidence ratio for women with family history of breast cancer was compared with SIR for women without family history of breast cancer (ratio). Bold denotes statistical significance; * denotes statistically significant ratio.

predisposition. By examining the influence of age at first cancer, family history of breast cancer, time since breast cancer, and their interaction, we aimed to explore the aetiology of second primary malignancies.

In our study, the SIRs for radiation-related solid tumours (e.g. oesophagus, lung, NHL, and connective tissue, particularly thorax and upper limbs) were higher in the 10 or more years follow-up period, whereas leukaemia risk was similar for both time periods.
Women diagnosed before the age of 50 years had a substantially higher risk for all cancer sites (except the endometrium, central nervous system, acute and chronic lymphatic leukaemia, and melanoma), possibly due to increased susceptibility as well as more aggressive treatment for breast cancer in younger women. Increased risks analysed as the ratio between women with and without a family history of breast cancer were seen in cancers of the oesophagus, stomach, ovary, NHL, and leukaemia. 
The almost six-fold higher risk of oesophagus cancer we found in women with a family history of breast cancer compared to women without a family history of breast cancer $\geqslant 10$ years following breast cancer diagnosis ( $\mathrm{SIR}=7.54$ vs 1.28 ) suggests an interaction between radiotherapy and inherited factors. In earlier studies, a high familial risk was found (Czene et al, 2002; EBCTCG, 2005). In addition, environmental factors such as tobacco and alcohol are important for oesophageal cancer and probably explain part of the familial clustering, although this could be due to chance, because the study was based on only five cases.

We found an increased risk of stomach cancer, which was significantly higher in women diagnosed with breast cancer before 50 and in women with a family history of breast cancer, suggesting a role of shared environmental and genetic factors. Rare syndromes such as $\mathrm{Li}$-Fraumeni syndrome and ataxia telangiectasia can explain little of the elevated risk (Bevan and Houlston, 1999).

As in other studies (Neugut et al, 1994) and consistent with the effects of radiotherapy, risks of lung cancer were greater with longer follow-up time and younger age at breast cancer diagnosis. We recently reported an interaction between ionising radiation and smoking in women with breast cancer where the risk of lung cancer was confined to smokers who received radiotherapy (Prochazka et al, 2005).

We found the highest risk of endometrial cancer among women aged 50 or older at breast cancer diagnosis in the 1-9 year followup period. Our age and temporal findings (risk was higher during the later study period, 1980-2000) are consistent with the effects of tamoxifen treatment starting in the late 1970s in women over age 50 (Bergman et al, 2000; Swerdlow and Jones, 2005). An increased risk of breast cancer after endometrial cancer has also been reported (Mellemkjaer et al, 2006). Shared risk factors such as early menarche, late menopause, and nulliparity (Bergman et al, 2000) probably also contributed to our findings.

$B R C A-1$ and $B R C A-2$ genes are known to be involved in inherited susceptibility to breast and ovarian cancer (Lindor and Greene, 1998; Welcsh and King, 2001) and may contribute to the 1.8-fold higher risk of second ovarian cancer we observed in women diagnosed with breast cancer at younger ages as well as the 1.7-fold higher risk in women with a family history of breast cancer compared with those without a family history of breast cancer.

We found an increased risk of melanoma for women with a family history of breast cancer, suggesting genetic influence. A number of studies have suggested mutations of $C D K N 2 A$ and $B R C A 2$ as possible determinants of the higher incidence of melanoma among breast cancer patients (Borg et al, 2000; Goggins et al, 2004).

\section{REFERENCES}

Bergman L, Beelen ML, Gallee MP, Hollema H, Benraadt J, van Leeuwen FE (2000) Risk and prognosis of endometrial cancer after tamoxifen for breast cancer. Comprehensive Cancer Centres' ALERT Group. Assessment of Liver and Endometrial cancer Risk following Tamoxifen. Lancet 356: $881-887$

Bevan S, Houlston RS (1999) Genetic predisposition to gastric cancer. Q J Med 92: 5-10

Borg A, Sandberg T, Nilsson K, Johannsson O, Klinker M, Masback A, Westerdahl J, Olsson H, Ingvar C (2000) High frequency of multiple melanomas and breast and pancreas carcinomas in CDKN2A mutationpositive melanoma families. J Natl Cancer Inst 92: 1260-1266

Breslow NE, Day NE (1987) Statistical Methods in Cancer Research. Volume II - The Design and Analysis of Cohort Studies IARC Scientific Publications No. 82 Lyon: International Agency for Research on Cancer

Clayton D, Hill M (1993) Statistical Models in Epidemiology. Oxford University Press Inc.: New York

Czene K, Lichtenstein P, Hemminki K (2002) Environmental and heritable causes of cancer among 9.6 million individuals in the Swedish FamilyCancer Database. Int J Cancer 99: 260-266
We found a higher overall risk of a connective tissue malignancy with a longer follow-up time. However, when age and time since breast cancer diagnosis were considered jointly, an almost five-fold risk was observed in women $<50$ years old within the first 10 years following breast cancer diagnosis. The risk was even more pronounced in connective tissue cancers of the thorax or upper limbs, parts often included in the radiation field during breast cancer treatment, as previously reported (Harvey and Brinton, 1985; Kirova et al, 2005).

In agreement with previous reports, we found that the risk of NHL increased with time (Harvey and Brinton, 1985). In our study, the risk $\geqslant 10$ years after breast cancer diagnosis was four times higher in women with a family history of breast cancer compared to those without a family history, suggesting possible interaction of treatment with genetic factors.

A review (van Leeuwen and Travis, 2001) as well as later work (Smith et al, 2003; Raymond and Hogue, 2006) reported that alkylating agents/radiotherapy increased the risk of leukaemia beginning 1-2 years following treatment and peaking at 5-10 years after treatment, consistent with our results. We also found an elevated risk of leukaemia in women with a family history of breast malignancy.

The strengths of our study are the population-based design, complete follow-up of all patients, and the ability to identify women with a family history of breast cancer. We excluded malignancies diagnosed during the first year of follow-up avoiding detection of indolent tumours by increased surveillance. Among limitations we could not identify potential treatment effects because therapy information is not recorded in the cancer register.

In conclusion, we found that women diagnosed with breast cancer had a $22 \%$ increased risk of developing a second primary non-breast malignancy. Women with breast cancer before age 50 and women with a family history of breast cancer had elevated risks of developing several cancers, indicating a genetic predisposition to develop multiple tumours and/or susceptibility to the carcinogenic effect of breast cancer therapy.

\section{ACKNOWLEDGEMENTS}

We thank Linda Morris Brown DrPH (Division of Cancer Epidemiology and Genetics, Department of Health and Human Services, National Cancer Institute, National Institutes of Health, Bethesda, MD, USA) for her helpful and critical review of the manuscript during formative stages.
EBCTCG (2005) Effects of chemotherapy and hormonal therapy for early breast cancer on recurrence and 15-year survival: an overview of the randomised trials. Lancet 365: 1687-1717

Edlich RF, Winters KL, Lin KY (2005) Breast cancer and ovarian cancer genetics. J Long Term Eff Med Implants 15: 533-545

Goggins W, Gao W, Tsao H (2004) Association between female breast cancer and cutaneous melanoma. Int J Cancer 111: $792-794$

Harvey EB, Brinton LA (1985) Second cancer following cancer of the breast in Connecticut, 1935-82. Natl Cancer Inst Monogr 68: 99-112

Hemminki K, Li X, Plna K, Granstrom C, Vaittinen P (2001) The nationwide Swedish family-cancer database - updated structure and familial rates. Acta Oncol 40: $772-777$

Karlsson P, Holmberg E, Samuelsson A, Johansson KA, Wallgren A (1998) Soft tissue sarcoma after treatment for breast cancer - a Swedish population-based study. Eur J Cancer 34: 2068-2075

Kirova YM, Vilcoq JR, Asselain B, Sastre-Garau X, Fourquet A (2005) Radiation-induced sarcomas after radiotherapy for breast carcinoma: a large-scale single-institution review. Cancer 104: $856-863$ 
Levi F, Te VC, Randimbison L, La Vecchia C (2003) Cancer risk in women with previous breast cancer. Ann Oncol 14: 71-73

Lindor N, Greene MH (1998) Familial Cancer Program. The consice handbook of family cancer syndromes. Special article. J Natl Cancer Inst 90: $1039-1071$

Mattsson B, Wallgren A (1984) Completeness of the Swedish Cancer Register. Non-notified cancer cases recorded on death certificates in 1978. Acta Radiol Oncol 23: 305-313

McClain MR, Palomaki GE, Nathanson KL, Haddow JE (2005) Adjusting the estimated proportion of breast cancer cases associated with BRCA1 and BRCA2 mutations: public health implications. Genet Med 7: 28-33

Mellemkjaer L, Friis S, Olsen JH, Scelo G, Hemminki K, Tracey E, Andersen A, Brewster DH, Pukkala E, McBride ML, Kliewer EV, Tonita JM, KeeSeng C, Pompe-Kirn V, Martos C, Jonasson JG, Boffetta P, Brennan P (2006) Risk of second cancer among women with breast cancer. Int J Cancer 118: 2285-2292

Neugut AI, Murray T, Santos J, Amols H, Hayes MK, Flannery JT, Robinson E (1994) Increased risk of lung cancer after breast cancer radiation therapy in cigarette smokers [see comments]. Cancer 73: 1615-1620

Prochazka M, Granath F, Ekbom A, Shields PG, Hall P (2002) Lung cancer risks in women with previous breast cancer. Eur J Cancer 38: 1520 - 1525

Prochazka M, Hall P, Gagliardi G, Granath F, Nilsson BN, Shields PG, Tennis $\mathrm{M}$, Czene $\mathrm{K}$ (2005) Ionizing radiation and tobacco use increases the risk of a subsequent lung carcinoma in women with breast cancer: case-only design. J Clin Oncol 23: 7467

Raymond JS, Hogue CJ (2006) Multiple primary tumours in women following breast cancer, 1973-2000. Br J Cancer 94: 1745-1750
Shapiro CL, Recht A (1994) Late effects of adjuvant therapy for breast cancer. J Natl Cancer Inst Monogr 16: $101-112$

Smith RE, Bryant J, DeCillis A, Anderson S (2003) Acute myeloid leukemia and myelodysplastic syndrome after doxorubicin-cyclophosphamide adjuvant therapy for operable breast cancer: the National Surgical Adjuvant Breast and Bowel Project Experience. J Clin Oncol 21: $1195-1204$

Suzuki R, Ye W, Rylander-Rudqvist T, Saji S, Colditz GA, Wolk A (2005) Alcohol and postmenopausal breast cancer risk defined by estrogen and progesterone receptor status: a prospective cohort study. J Natl Cancer Inst 97: $1601-1608$

Swerdlow AJ, Jones ME (2005) Tamoxifen treatment for breast cancer and risk of endometrial cancer: a case-control study. J Natl Cancer Inst 97: $375-384$

Travis LB (2002) Therapy-associated solid tumors. Acta Oncol 41: 323-333 van Leeuwen FE, Travis LB (2001) Second cancers. In Cancer: Principles and Practice of Oncology DeVita VT, Hellman S, Rosenberg SA (eds) pp 2939-2964. Philadelphia: Lippincott Williams \& Wilkins

Welcsh PL, King MC (2001) BRCA1 and BRCA2 and the genetics of breast and ovarian cancer. Hum Mol Genet 10: 705-773

Yu GP, Schantz SP, Neugut AI, Zhang ZF (2006) Incidences and trends of second cancers in female breast cancer patients: a fixed inception cohort-based analysis (United States). Cancer Causes Control 17: $411-420$

Zablotska LB, Chak A, Das A, Neugut AI (2005) Increased risk of squamous cell esophageal cancer after adjuvant radiation therapy for primary breast cancer. Am J Epidemiol 161: 330-337 